\title{
The Hologenome Concept of Evolution: Medical Implications
}

\author{
Eugene Rosenberg, Ph.D.* and Ilana Zilber-Rosenberg, Ph.D. \\ Department of Molecular Microbiology and Biotechnology, Tel Aviv University, Ramat Aviv, Israel
}

\begin{abstract}
All natural animals and plants are holobionts, consisting of the host and microbiome, which is composed of abundant and diverse microorganisms. Health and disease of holobionts depend as much on interactions between host and microbiome and within the microbiome, as on interactions between organs and body parts of the host. Recent evidence indicates that a significant fraction of the microbiome is transferred by a variety of mechanisms from parent to offspring for many generations. Genetic variation in holobionts can occur in the microbiome as well as in the host genome, and it occurs more rapidly and by more mechanisms in genomes of microbiomes than in host genomes (e.g. via acquisition of novel microbes and horizontal gene transfer of microbial genes into host chromosomes). Evidence discussed in this review supports the concept that holobionts with their hologenomes can be considered levels of selection in evolution. Though changes in the microbiome can lead to evolution of the holobiont, it can also lead to dysbiosis and diseases (e.g. obesity, diarrhea, inflammatory bowel disease, and autism). In practice, the possibility of manipulating microbiomes offers the potential to prevent and cure diseases.
\end{abstract}

KEY WORDS: Beneficial microbes, genetic variation, holobiont, hologenome, microbiome

\section{INTRODUCTION}

Biology is undergoing a paradigm change. Animals and plants can no longer be considered individuals. ${ }^{1}$ All are holobionts, consisting of the host and abundant and diverse microbiotas, which comprise bacteria, archaea, viruses, and protists. Symbioses be- tween microorganisms and animals/plants, once thought to be rare events, are actually a hallmark of eukaryotic life.

A decade ago, we published the hologenome concept of evolution, which posits that the holobiont, in

\footnotetext{
Abbreviations: ASDs, autism spectrum disorders; CD, Crohn's disease; IBD, inflammatory bowel disease; FMT, fecal microbiota transplantation.

Citation: Rosenberg E, Zilber-Rosenberg I. The Hologenome Concept of Evolution: Medical Implications. Rambam Maimonides Med J 2019;10 (1):eooo5. Review. doi:10.5041/RMMJ.10359

Copyright: (C) 2019 Rosenberg and Zilber-Rosenberg. This is an open-access article. All its content, except where otherwise noted, is distributed under the terms of the Creative Commons Attribution License (http://creativecommons.org/licenses/by/3.o), which permits unrestricted use, distribution, and reproduction in any medium, provided the original work is properly cited.
}

Conflict of interest: No potential conflict of interest relevant to this article was reported.

* To whom correspondence should be addressed. E-mail: eros@post.tau.ac.il 
concert with its hologenome, is a level of selection in evolution. ${ }^{2,3}$ Considerable data have accumulated since the concept was first proposed that support and enrich it. 4 Much of the data have come from the development of DNA-based techniques for analyzing bacterial communities, without having to culture them.

As soon as the right method was found, discoveries came as easily as ripe apples from a tree. (Robert Koch, 1905 Nobel Prize Laureate in Physiology or Medicine)

Though there have been a number of recent reviews on the role of the microbiome in human health and disease, ${ }^{-10}$ in this review we wish to briefly describe the hologenome concept and discuss how it offers new perspectives to modern medicine.

\section{Box A. Definitions}

Bacterial species: the most widely used bacterial species definition is a group of strains showing over $97 \%$ of $16 \mathrm{~S}$ rDNA gene-sequence identity.

Holobiont: a term introduced by Margulis, ${ }^{11}$ which now refers to the host plus the entire microbiome.

Hologenome: the union of all the genes in a holobiont, i.e. the host genome plus all of the genomes of the microbiome. ${ }^{3}$

Horizontal gene transfer (HGT): transfer of groups of genes between bacteria of different taxa and from microbiomes to their hosts.

Horizontal transmission of microbiota: transfer of microorganisms from parent to offspring via the environment.

Microbiome: the community of symbiotic microorganisms. ${ }^{12}$

Microbiota: microorganisms in the microbiome, but not necessarily all of it.

Symbiosis: the term was first coined by Anton de Bary in the mid-nineteenth century as "the living together of different species."3(p.276) This broad definition is generally accepted, and easily comes to terms with the hologenome concept. The symbiotic system is usually constructed from a large partner termed the host and smaller partners called symbionts. A symbiont can be mutualistic, commensal, or pathogenic.

Vertical transmission of microbiota: transfer from parent to offspring without mixing with microorganisms from the environment. ${ }^{13}$

\section{THE HOLOGENOME CONCEPT OF EVOLUTION}

The hologenome concept of evolution is based on four generalizations:

1. All natural animals and plants are holobionts containing abundant and diverse microbiota.

2. Holobionts can function as distinct biological entities, anatomically, metabolically, immunologically, during development and in evolution. Microbiomes participate in achieving fitness of the holobionts.

3. A significant fraction of the microbiome genome together with the host genome is transmitted from one generation to the next, and thus can propagate unique properties of the holobiont.

4. Genetic variation in holobionts can occur by changes in the host and/or microbiome genomes. Since the microbiome genome can adjust to environmental dynamics more rapidly and by more processes than the host genome, it can play a fundamental role in adaptation and evolution of holobionts.

\section{Plants, Animals, and Humans are \\ Holobionts}

Development of non-culturing, DNA-based methods for analyzing bacterial communities has led to the determination of bacterial species diversity in a wide assortment of non-vertebrates, vertebrates, and plants. It is now clear that all natural animals and plants contain hundreds or thousands of different bacterial species as well as abundant viruses ${ }^{14}$ and often fungi15; the two last-mentioned have not been studied extensively to date. For example, it has been reported that the human gut contains 5,700 bacterial species, ${ }^{16}$ and human skin contains 1,000 species. ${ }^{17}$ These are minimum numbers since rare species cannot be determined by current methods. Because of the large diversity of bacterial species, the gut microbiome contains ca. 9 million unique protein-coding genes or 400 times more bacterial genes than human genes. ${ }^{18}$

One of the unexpected findings of studies of gut microbiomes is the enormous variation between individual humans; the bacterial species composition within the human gut is unique to each person. Nevertheless, microbiomes of different individuals are closer to each other than to microbiomes of other primates, ${ }^{19}$ suggesting that there is something com- 
mon (a core) to the human microbiome. Shapira ${ }^{20}$ has discussed the differences between conserved core microbiota and flexible, environmentally driven microbiota, with regard to their maintenance and contributions to host adaptation. It should be emphasized that "presence" or "absence" of a bacterial species depends on technical limits of detection. Methods developed to detect rare species may reveal that there are many more common (core) species than currently considered and that individual variation may be the result of quantitative rather than qualitative differences that are caused by a different diet or other environmental factors. Foods, such as red wine, ${ }^{21}$ tea, coffee, ${ }^{22}$ and chocolate, ${ }^{23}$ food additives, such as food emulsifiers ${ }^{24}$ and artificial sweeteners, ${ }^{25}$ and essentially any material that is put in the mouth affect the gut microbiome at all ages. Also, microbiomes are affected by physical activity ${ }^{26}$ and illnesses, e.g. cancer ${ }^{27}$ and diabetes. ${ }^{28}$ Clearly, the complexity and dynamics of microbiomes are only beginning to be appreciated.

Microbiomes change also with age. Newborns are dominated by facultative anaerobes such as the Proteobacteria, after which the diversity of strict anaerobes within the Firmicutes and Bacteroidetes phyla increases towards a more adult-like profile by approximately one year. ${ }^{29,30}$ The microbiome in young children is shaped by mode of delivery, $3^{1}$ diet, $3^{2}$ exposure to environmental factors, such as furry pets, 33 and, of course, antibiotic treatment. 34 During most of adult life, the microbiome appears to be more or less stable. 35 In older people ( $>65$ years), however, the gut microbiome is extremely variable between individuals and differs from the microbiome of younger adults. ${ }^{36}$

\section{Microbiomes Affect the Fitness of Holobionts}

A large number of studies have demonstrated the beneficial interactions between microbiomes and their hosts, leading to a better-adapted holobiont. Table 1 summarizes major contributions of the microbiome to holobionts.

A large number of studies have shown that resident microbes protect holobionts from pathogens. For example, following oral infection, the numbers of Listeria monocytogenes were 10,000fold higher in the small intestine of germfree (GF) mice compared to conventional (CV) mice. ${ }^{37}$ Also Staphylococcus aureus infection is prevented by resident Corynebacterium species..$^{8}$ Blocking binding sites and production of antibiotics are two common mechanisms by which resident bacteria protect the holobiont against pathogens. ${ }^{39,40} \mathrm{~A}$ strong argument for the role of bacteria in combatting infectious disease is the successful treatment of patients, suffering from severe diarrhea caused by Clostridium difficile infection, with fecal transplants from healthy donors (see further on). 41

There are many examples of microbiomes contributing to their hosts by carrying out metabolic processes that the animal or plant is unable to carry out by itself. In humans, gut bacteria have been shown to perform many beneficial biochemical reactions, amongst them: (1) production of metabolites from dietary components, such as the conversion of dietary fiber to the short-chain fatty acids (SCFAs), acetate, propionate, and butyrate ${ }^{42}$ important for colonocyte health and regulatory activity of the body; (2) modification of metabolites that are produced

Table 1. Examples of Microbial Participation in the Fitness of Holobionts.

\begin{tabular}{|l|l|}
\hline \multicolumn{1}{|c|}{ Contribution of Microbiota } & \multicolumn{1}{c|}{ Examples } \\
\hline Protection against pathogens & Plants, animals, humans \\
Provides essential nutrients to host & SCFAs, AAs, vitamins \\
Fat storage and obesity & Shown in mice, chickens, and humans \\
Development & $\begin{array}{l}\text { Squid light organ, legume nodule, immune system, } \\
\text { angiogenesis, muscle thickness }\end{array}$ \\
Behavior & $\begin{array}{l}\text { Brain, metabolites, hormones, stress, autism, sleep, } \\
\text { mating selection, group living }\end{array}$ \\
Detoxification of toxic substances & Plant and fungal toxins in food, heavy metals \\
\hline AA, amino acids; SCFAs, short-chain fatty acids.
\end{tabular}


by the host, such as converting primary bile acids to secondary bile acids, thus assisting in bile acid recycling 43 ; (3) de novo synthesis of compounds, e.g. the important microbial immune modulator polysaccharide $\mathrm{A}$, produced by the common gut bacterium Bacteroides fragilis 44 ; and (4) synthesis of vitamin $\mathrm{K}$ as well as most of the water-soluble B vitamins. 45

The human microbiotas play a role in energy metabolism and obesity, as will be discussed later in the review, and, although gut bacteria contributing to obesity are generally considered harmful, under certain conditions they are also beneficial. During the third trimester of pregnancy, these so-called "obese bacteria" become abundant 46 and induce metabolic changes that promote energy storage in fat tissue that in turn encourages growth of the fetus and milk production in the mother. Also, during our evolution, food insecurity was a frequent occurrence, and the ability to store energy in the form of fat was probably advantageous for survival ("thrifty genotype hypothesis"47).

Symbiotic bacteria play a role in the development of animals and plants. For example, Rhizobia strains cooperate with legume plants to produce root nodules that perform nitrogen fixation, ${ }^{48}$ and Vibrio fischeri triggers the formation of the light organ in squid, where luminescence occurs helping the squid avoid predation. In humans and other vertebrates, the gut microbiome promotes the development of the immune system and body organs. Exposure to microorganisms educates the immune system, induces innate and adaptive immunity, 49 and initiates memory B and T cells that are essential to combat various pathogens. In addition, the gut microbiome encourages the development of bone mass ${ }^{50}$ and blood vessels in the intestinal wall. ${ }^{51}$

Gut microbiotas modulate brain development and behavior, including anxiety and mood disorders, 52,53 as will be discussed later in the review. Microbial gut-brain signaling is bidirectional. The circuitry of neurons, hormones, and chemical neurotransmitters enables messages to be transmitted between the brain and the gut. The gut microbiota influences the body's level of the potent neurotransmitter serotonin, which promotes feelings of happiness and peacefulness. 54 Conversely, the rate at which food is being moved and how much mucus is lining the gut-both of which can be controlled by the brainhave a direct impact on gut microbiota.

\section{Transmission}

The mechanism for transmission of host DNA to offspring is well understood and need not be discussed here. Transmission of the microbiome from parent to offspring also occurs, but with a variety of mechanisms: (1) vegetative reproduction in plants and many animals, such as worms and corals (vertical transmission); (2) via oocytes in sponges, herbs, and many insects (vertical transmission); (3) coprophagy (eating the feces of parents) in many animal species (both vertical and horizontal transmission); (4) physical contact starting at birth in most animals, including humans (both vertical and horizontal); and (5) mother's milk in mammals (vertical).

In humans, transmission to the offspring occurs initially via inoculation with maternal vaginal and fecal microbes when the baby transits the birth channel (vertical transmission). Kissing and hugging provides additional microbiota to the offspring. Breastfeeding is an additional route of maternal vertical microbial transmission.55 Human milk contains ca. $10^{5}$ bacteria per $\mathrm{mL}$, composed of hundreds of species. ${ }^{6}$ Analyses of the DNA of several bacterial strains isolated from mother's milk demonstrated that they were identical to those found in the offspring, 57 providing support for vertical transmission. Mother's milk is also a continuous source of modified oligosaccharides that support the growth of these bacteria but are not digestible by the infant..$^{8}$ In essence, these oligosaccharides function as natural prebiotics. The Bifidobacterium species contain unique genetic loci responsible for vigorous growth on these oligosaccharides, 59 suggesting a remarkable co-evolution between the symbiotic bacteria and their human host, benefiting both.

Long-term transmission of microbiota in great apes, including humans, was studied using both $16 \mathrm{~S}$ ribosomal gene sequences ${ }^{60}$ and rapidly evolving gyrB gene sequences. ${ }^{61}$ The host species phylogenies based on the composition of these microbial communities were completely congruent with the known evolutionary relationships of the hosts. The authors concluded that over evolutionary timescales the composition of the gut microbiota among great ape species is phylogenetically conserved and has diverged in a manner consistent with vertical inheritance. 


\section{Genetic Variation and Evolution of Holobionts}

Genetic variation occurs more rapidly in genomes of microorganisms than in host genomes, thereby offering a potential for manipulating the microbiome to prevent and treat certain diseases of holobionts. Genetic variation in holobionts can occur, in addition to mutation and DNA rearrangement, also by three other mechanisms: (1) amplification or reduction of specific microbes, (2) acquisition of novel microbes from the environment, and (3) horizontal gene transfer from microbes to microbe or from microbe to host.

Amplification/reduction refers to the increase/ decrease of one group of symbionts relative to others. This can occur rapidly when conditions change. An increase in the number of a particular microbe is equivalent to amplification of a whole set of genes. Considering the large amount of genetic information encoded in the diverse microbial population of holobionts, microbial amplification/reduction can be a powerful mechanism for contributing to adaptation, development, and evolution of holobionts. Since genetic variation by amplification is driven by the environment, it has a Lamarckian aspect to it. ${ }^{62}$ Amplification is also a crucial step in genetic variation by acquisition of novel microbes because pioneer microbes need to amplify in order to become established in its host.

Animals, including humans, and plants come into contact with billions of microorganisms during their lifetime, via air, water, and interaction with organic and inorganic surfaces. Occasionally some of these microbes will find a niche and under appropriate conditions will amplify in the host and become part of the microbiome. Acquisition of a microbe introduces hundreds of new genes into the holobiont. Rather than trying to create genes that have already evolved in microbes, animals and plants acquired pre-evolved genetic information in the form of microbes. Microbes were on this planet for 2.1 billion years before there were any animals or plants. During this time, they developed into organisms encompassing enormous biochemical diversity. The first eukaryote was probably formed by the acquisition of bacteria to eventually form mitochondria ${ }^{63}$ and chloroplasts. ${ }^{64}$ Uptake of microbes into multicellular organisms continued to provide genetic variation for holobionts throughout evolution.

An example of a major evolutionary event that was driven by the acquisition of bacteria is the ability of many animals, including humans, to use plant fibers as nutrients. ${ }^{65}$ However, animal genomes do not contain the information for synthesizing enzymes that degrade the complex polysaccharides in plant material. Instead, they rely on microorganisms that are present in their digestive tract. These microbes anaerobically convert polysaccharides to fatty acids that are a source of carbon and energy for their host animal. It is likely that these bacteria were acquired by a gradual process of internalizing them from the soil. Instead of plant fiber being broken down in the soil prior to ingestion, it "rots" in the gut after consumption.

Another important mode of genetic variation in holobionts, referred to as horizontal gene transfer (HGT), involves the transfer of groups of genes between bacteria of different taxa and from microbiomes to their host. Intimate contact between microbes and between microbes and host in holobionts would promote HGT. It has been suggested that nutritional adaptation is one of the key selective pressures on the microbiome in the mammalian gut, and that HGT processes contribute to that adaptation. ${ }^{66}$ Until 2010, only a few examples of HGT events were recognized in which genes from microbes were transferred sometime in the past to animals. These included transfer of: Wolbachia genes to the chromosomes of their insect hosts, ${ }^{67}$ bacterial and fungal genes into the telomere region of rotifers, ${ }^{68}$ fungal genes to aphids, ${ }^{69}$ and cellulose genes from bacteria to nematodes. ${ }^{70}$ However, an examination of a large number of high-quality genomes, that became available recently, has led to the conclusion that HGT in animals and plants was a general phenomenon that resulted in the incorporation of tens or even hundreds of active foreign genes into the eukaryotic genome. ${ }^{71}$

In humans, 145 genes (not present in other primates) were attributed to HGT. ${ }^{2}$ These genes are distributed throughout the genome and play a variety of roles, such as amino-acid metabolism (2 genes), macromolecule modifications (15 genes), lipid metabolism (13 genes), antioxidant activities (5 genes), and innate immune response (7 genes). Most of the $\mathbf{1 4 5}$ genes identified in the study came from bacteria, but some originated from viruses and yeasts. Analysis of a moss identified 128 genes found in land plants but absent from algae.73 These genes were acquired by HGT from prokaryotes, fungi, or viruses. Many of these genes are involved in some essential plant-specific activities, such as xylem formation, plant defense, nitrogen recycling, and the 
biosynthesis of starch, polyamines, hormones, and glutathione.

A key event in the evolution of placental mammals was the acquisition by HGT, from a retrovirus, of the gene coding for the protein syncytin.74 Initially, the function of syncytin was to allow retroviruses to fuse host cells so that viruses could move from one cell to another. Now, syncytin is necessary for the development of the placental syncytium, an essential part of the mother-fetus barrier. In addition, retroviral-derived DNA appears to have played a crucial function in the generation of the progesterone-sensitive uterine decidual cell, allowing nutrient provision to the developing embryo. 75 These data indicate that the integration of viral DNA into host genomes by HGT played a primary role in major evolutionary events.

Horizontal gene transfer (HGT) from microbe to microbe can also affect human metabolism and evolution. An example is the ability of Japanese to break down agar (an abundant ingredient in their diet) since they have a bacterium in their gut that contains genes that code for the porphyranases that degrade the polysaccharide agarose of agar. Westerners lack this bacterium in their gut and therefore cannot digest agar. The group of genes coding for agarose digestion was driven into a resident gut bacterium by HGT from a marine bacterium that was present on raw seaweed. ${ }^{76}$ Bacteria with the transferred genes spread throughout the Japanese population by vertical and horizontal transmission.

In summary, the evidence brought forth up to now in this review supports the concept that holobionts with their hologenomes can be considered levels of selection in evolution. Furthermore, genetic variation and the evolution of holobionts involve, in addition to classical genetic variations in the host, also acquisition of novel microbes and HGT of microbial genes into host chromosomes. In the following section, we will be discussing the relationship between the hologenome concept and some human diseases, thereby reinforcing the holobiont as a unified biological entity.

\section{HOW DOES THE HOLOGENOME CONCEPT RELATE TO MEDICINE?}

Although we are only beginning to understand what constitutes a healthy microbiome, there is already considerable data indicating significant differences between microbiomes of diseased compared to healthy holobionts. Pitlik and Koren ${ }^{77}$ have hypothesized that probably every illness of holobionts, acute or chronic, is accompanied by some perturbation of the microbiome. This hypothesis is a logical outcome of the hologenome concept and is based on the tight interdependence of the host and its microbiome. Any disturbance in the delicate equilibrium of host-microbiome interactions can on the one hand participate in disease causation, or, on the other hand, because of changing internal conditions, be a result of it.

In previous sections of this review, we have described beneficial aspects of the microbiomes, those that participate in the functioning of healthy holobionts, as we know them. In this section, we wish to discuss the evidence demonstrating that alteration of the microbiome can lead to dysbiosis and disease of the holobiont, and, in selected cases, exemplifying general principles, we will examine how they do it. We will also discuss how manipulation of the microbiome has the potential to prevent or cure certain diseases by reaching a new healthier equilibrium.

\section{Obesity and Metabolic Diseases}

The twin epidemics of obesity and type 2 diabetes have generated considerable research and information in the last 20 years, including a growing awareness of the role of the microbiome. Understanding of the complex metabolic interplay observed within the holobiont led to milestone studies, more than a decade ago, showing the involvement of microbiota in fat storage ${ }^{78}$ and the existence of a different microbiota in obese humans as compared to normalweight people. 79 These studies also demonstrated reduced microbial diversity in obesity, altered bacterial genes and pathways, ${ }^{80}$ and an abundance of Firmicutes compared to Bacteroidetes. ${ }^{81}$ The picture perceived today, regarding the involvement of the microbiome in obesity of humans, seems to be more complex and depends on several variables, such as on the technique used for determining bacterial species and numbers, the age, sex, and ethnicity of the subjects, and the location of the microbes in the gut. ${ }^{82,83}$ It may well be that differences in microbiotas also depend on extent of obesity, becoming more pronounced as the BMI is elevated and abdominal fat is greater, as has been shown comparing microbial gene richness in people with very high BMI and those with lower BMI. ${ }^{84}$ Because of the complex interactions of gut microbiota with the human body, the mechanisms underlying the 
network between obesity and microbiota probably are manifold and heterogeneous. The most likely mechanisms were summarized in a number of reviews ${ }^{85}-87$ and include: increase in energy harvest by the "obese microbiome"; lower short-chain fatty acid production influencing a cascade of regulatory activities; greater intestinal permeability causing leakage of bacterial endotoxins into the blood; low-grade inflammation affecting adipogenesis and other targets; impact on toll-like receptors; and increased endocannabinoid receptor system tone.

Obese microbiotas with their metabolic effects have been implicated in metabolic diseases especially in the metabolic syndrome and in type 2 diabetes, in addition to cardiovascular disease and fatty liver. $5,87-90$ Obese microbiotas have also been implicated in certain types of cancer. ${ }^{91,92}$ It should be noted that in spite of their pathological role, "obese bacteria" are also associated with weight gain during the third trimester of pregnancy, as noted in a previous section, so caution should be used in considering these obese bacteria as only being harmful. 46

The empirical demonstration that microbiotas can have a causal effect on obesity and other metabolic diseases has inspired investigators to test probiotics and prebiotics for the treatment of these diseases. Most of the published experiments on obesity treatment were with animals. The few human studies have been inconclusive. 87,93 The potential of microbiome-targeted therapies for obesity and metabolic diseases has recently been reviewed, 87,94 and therapies include probiotics, prebiotics, and fecal transplant, in addition to indirect effects such as via medications or metabolic surgery. In our opinion, based on the hologenome concept of genetic variation by amplification/reduction, successful prevention or treatment of obesity and metabolic diseases by changing microbiota will require a parallel change in gut environment. For instance, maintaining an appropriate long-term diet, thereby conserving a useful concentration of the beneficial microbiota.

\section{Diarrhea Caused by Clostridium difficile}

The major success in the use of microbiota to treat disease is fecal transplants from healthy donors for the treatment of diarrhea caused by Clostridium difficile. Fecal microbiota transplantation (FMT) is a treatment that involves administration of minimally manipulated microbial community from stool of a healthy donor into the patient's intestinal tract. The transplant material can be delivered by various routes, including an encapsulated form as an oral medication. ${ }^{95}$ Hundreds of patients with reoccurring diarrhea caused by antibiotic-resistant $C$. difficile have been treated by FMT with an average cure rate of $90.4 \% .^{41} \mathrm{~A}$ recent study on a small number of patients reinforced previous findings that fecal transplantation was also better than antibiotics for primary treatment of $C$. difficile infections. ${ }^{96}$

Most of the patients that were treated by FMT had previously been exposed to multiple courses of antibiotics. Not surprisingly, these patients had a greatly disturbed microbiome, with a complete disappearance of Bacteroidetes, reduction in Firmicutes, increase in Proteobacteria, and a general loss of microbial diversity. ${ }^{77}$ Fecal microbiota transplantation (FMT) normalizes the composition and functionality of gut microbiota as early as $24 \mathrm{~h}$ after treatment.98,99 Four mechanisms have been suggested to explain how FMT restores normal gut microbial community structure and functionality:100 (1) Direct competition of healthy commensal microbiota delivered by FMT with $C$. difficile for space and nutrients; (2) restoration of secondary bile acid metabolism in the colon; (3) repair of the gut barrier by stimulation of the mucosal immune system; and (4) bacterial production of bacteriocins, such as thuricin and nisin, which are antimicrobial peptides with bactericidal activity against $C$. difficile..$^{101,102}$

\section{Inflammatory Bowel Disease (IBD)}

Recent studies using improved DNA technology have shown that IBD is associated with characteristic shifts in the composition of the gut microbiome, suggesting that IBD results from altered interactions between intestinal microbes and the mucosal immune system. ${ }^{103}$ The concept of an altered collective gut microbiota rather than identification of a single culprit is possibly the most significant development in IBD research. In general, IBD studies show an overall decrease in biodiversity, a decreased representation of several taxa within the Firmicutes phylum, and an increase in the Gammaproteobacteria, which were also found in pairs of monozygotic twins discordant for Crohn's disease (CD). ${ }^{104}$ There is a reduced diversity in inflamed versus noninflamed areas of the gut, even within the same patient, and CD patients have a lower overall bacterial abundance at inflamed regions. ${ }^{105}$

Studies on how manipulation of the microbiome can be used to treat IBD fall into three broad categories: (1) antibiotics to reduce inflammatory bacteria, (2) modification of the gut environment through diet and prebiotics to encourage the growth of bene- 
ficial bacteria, and (3) direct introduction of beneficial bacteria via probiotics or FMT. Epidemiological, experimental, and clinical evidence of the current status of these three potential treatments has recently been reviewed, leading to the conclusion that "it is currently challenging to elegantly translate results into clinical practice."106,107(p.26)

\section{Autism Spectrum Disorders (ASDs)}

Autism spectrum disorders (ASDs) are neurodevelopmental conditions characterized by social and behavioral impairments, often accompanied by gastrointestinal abnormalities. Several studies have shown an altered gut microbiome associated with ASDs, both in bacterial and fungal communities. ${ }^{108-110}$ Autistic children have a significant increase in the Firmicutes/Bacteroidetes ratio due to significant reduction of Bacteroidetes. At the genus level, autistic subjects have a significantly higher abundance of Collinsella, Corynebacterium, Dorea, Lactobacillus, and Candida, and a reduced abundance of Alistipes, Bilophila, Dialister, Parabacteroides, and Veillonella compared to healthy subjects.

Evidence suggests an early immune activation with chronic inflammation and cytokine dysregulation in ASDs. ${ }^{111}$ In animal studies, it has been shown that systemic inflammation induced by lipopolysaccharide provokes behavioral changes and impairs the blood-brain barrier. ${ }^{112}$ One of the strongest arguments for the role of bacteria in ASDs is the report that oral treatment of mice that display features of ASD with the human commensal Bacteroides fragilis corrects gut permeability, alters microbial composition, and ameliorates defects in communicative, anxiety-like, sensorimotor, and other stereotypic behaviors. ${ }^{113}$ Furthermore, the treatment altered several metabolites that are known to affect the brain. These data support a general gutmicrobiome-brain connection which is pathologically pronounced in ASD, and suggest potential probiotic therapy for human ASDs, and possibly other behavioral problems.

\section{CONCLUSIONS}

There is now abundant evidence supporting the hologenome concept, which posits that the holobiont with its hologenome is a level of selection in evolution. However, the complexity and dynamics of holobionts are only beginning to be understood. What is clear is that most environmental elements affecting the holobiont, such as materials entering the digestive tract, can alter the microbiome and lead to adaptation and evolution, but also to dysbiosis and disease. Many diseases can only be understood by considering the patient as a holobiont, a complex system of interacting microbes and host. Moreover, the microbiome interacts with the host as do organs and body parts. Most of the time the interaction benefits the host, but sometimes it also causes harm. In practice, one of the challenges of modern medicine is to manipulate the microbiome so that it will prevent or cure certain diseases.

\section{REFERENCES}

1. Gilbert SF, Sapp J, Tauber AI. A symbiotic view of life: we have never been individuals. Q Rev Biol 2012;87:325-41. $\underline{\text { Crossref }}$

2. Rosenberg E, Koren O, Reshef L, Efrony R, ZilberRosenberg I. The role of microorganisms in coral health, disease and evolution. Nat Rev Microbiol 2007;5:355-62. Crossref

3. Zilber-Rosenberg I, Rosenberg E. Role of microorganisms in the evolution of animals and plants: the hologenome theory of evolution. FEMS Microbiol Rev 2008;32:723-35. $\underline{\text { Crossref }}$

4. Rosenberg E, Zilber-Rosenberg I. The hologenome concept of evolution-after ten years. Microbiome 2018;6:78. $\underline{\text { Crossref }}$

5. Young VB, The role of the microbiome in human health and disease: an introduction for clinicians. BMJ 2017;356:j831.

6. Mimee M, Citorik RJ, Lu TK. Microbiome therapeutics-advances and challenges. Adv Drug Deliv Rev 2016;105(Pt A):44-54.

7. McDonald D, Birmingham A, Knight R. Context and the human microbiome. Microbiome 2015;3:52. Crossref

8. Lynch SV, Pedersen O. The human intestinal microbiome in health and disease. N Engl J Med 2016;375: 2369-79. Crossref

9. Arrieta MC, Stiemsma L, Amenyogbe N, Brown EM, Finlay B. The intestinal microbiome in early life: health and disease. Front Immunol 2014;5:427. Crossref

10. Ghaisas S, Maher J, Kanthasamy A. Gut microbiome in health and disease: linking the microbiome-gutbrain axis and environmental factors in the pathogenesis of systemic and neurodegenerative diseases. Pharmacol Ther 2016;158:52-62. $\underline{\text { Crossref }}$

11. Margulis L. Symbiosis in Cell Evolution: Microbial Communities in the Archean and Proterozoic Eons. 2nd ed. New York: W.H. Freeman and Co; 1993. 
12. Lederberg J, McCray AT. 'Ome sweet 'omics-a genealogical treasury of words. The Scientist 2001;15:8.

13. Roughgarden J, Gilbert SF, Rosenberg E, ZilberRosenberg I, Lloyd EA. Holobionts as units of selection and a model of their population dynamics and evolution. Biological Theory 2018;13:44-65. Crossref

14. Ogilvie LA, Jones BV. The human gut virome: a multifaceted majority. Front Microbiol 2015;6:918. Crossref

15. Hoffmann C, Dollive S, Grunberg S, et al. Archaea and fungi of the human gut microbiome: correlations with diet and bacterial residents. PLoS One 2013; 8:e66019. Crossref

16. Nam YD, Jung MJ, Roh SW, Kim MS, Bae JW. Comparative analysis of Korean human gut microbiota by barcoded pyrosequencing. PLoS One 2011;6:e22109. Crossref

17. Ying S, Zeng D-N, Chi L, et al. The influence of age and gender on skin-associated microbial communities in urban and rural human populations. PLoS One 2015;10:e0141842. Crossref

18. Yang X, Xie L, Li Y, Wei C. More than 9,00o,ooo unique genes in human gut bacterial community: estimating gene numbers inside a human body. PLoS One 2009;4:e6074. Crossref

19. Ley RE, Lozupone CA, Hamady M, et al. Worlds within worlds: evolution of the vertebrate gut microbiota. Nat Rev Microbiol 2008;6:776-88. Crossref

20. Shapira M. Gut microbiotas and host evolution: scaling up symbiosis. Trends Ecol Evol 2016;31:539-49. Crossref

21. Queipo-Ortuno MI, Boto-Ordónez M, Murri M, et al. Influence of red wine polyphenols and ethanol on the gut microbiota ecology and biochemical biomarkers. Am J Clin Nutr 2012;95:1323-34. $\underline{\text { Crossref }}$

22. Zhernakova A, Kurilshikov A, Bonder MJ, et al. Population-based metagenomics analysis reveals markers for gut microbiome composition and diversity. Science 2016;352:565-9. Crossref

23. Tzounis X, Rodriguez-Mateos A, Vulevic J, Gibson GR, Kwik-Uribe C, Spencer J. Prebiotic evaluation of cocoa-derived flavanols in healthy humans by using a randomized, controlled, double-blind, crossover intervention study. Am J Clin Nutr 2011;93:62-72. Crossref

24. Chassaing B, Koren O, Goodrich JK, et al. Dietary emulsifiers impact the mouse gut microbiota promoting colitis and metabolic syndrome. Nature 2013;519: 92-6. Crossref

25. Suez J, Korem T, Zeevi D, et al. Artificial sweeteners induce glucose intolerance by altering the gut microbiota. Nature 2014;514:181-6. Crossref
26. Mach N, Fuster-Botella D. Endurance exercise and gut microbiota: a review. J Sport Health Sci 2017; 6:179-97. Crossref

27. Wang T, Cai G, Qiu Y, et al. Structural segregation of gut microbiota between colorectal cancer patients and healthy volunteers. ISME J 2012;6:320-32. Crossref

28. Qin J, Yingrui Li Y, Cai Z, et al. A metagenome-wide association study of gut microbiota in type 2 diabetes. Nature 2012;490:55-60. $\underline{\text { Crossref }}$

29. Bäckhed F, Roswall J, Peng Y, et al. Dynamics and stabilization of the human gut microbiome during the first year of life. Cell Host Microbe 2015;17:690-703. Crossref

30. Mueller NT, Bakacs E, Combellick J, et al. The infant microbiome development: mom matters. Trends Mol Med 2014;21:109-17. $\underline{\text { Crossref }}$

31. Song SJ, Dominguez-Bello MG, Knight R. How delivery mode and feeding can shape the bacterial community in the infant gut. CMAJ 2013;185:373-4. Crossref

32. Pop M. We are what we eat: how the diet of infants affects their gut microbiome. Genome Biol 2012; 13:152. Crossref

33. Tun HM, Konya T, Takaro TK, et al. Exposure to household furry pets influences the gut microbiota of infants at 3-4 months following various birth scenarios. Microbiome 2017;5:40. Crossref

34. Yassour M, Vatanen T, Siljander H, et al. Natural history of the infant gut microbiome and impact of antibiotic treatment on bacterial strain diversity and stability. Sci Transl Med 2016;8:343ra81. $\underline{\text { Crossref }}$

35. Zoetendal EG, Akkermans AD, De Vos W. Temperature gradient gel electrophoresis analysis of 16S rRNA from human fecal samples reveals stable and hostspecific communities of active bacteria. Appl Environ Microbiol 1998;64:3854-9.

36. Claesson MJ, Cusack S, O'Sullivan O, et al. Composition, variability, and temporal stability of the intestinal microbiota of the elderly. Proc Natl Acad Sci U S A 2011;108:4586-91. $\underline{\text { Crossref }}$

37. Archambau C, Sismeirod O, Toedling J, et al. The intestinal microbiota interferes with the microRNA response upon oral Listeria infection. MBio 2013; 4:e00707-13.

38. Ramsey MM, Freire MO, Gabrilska RA, Rumbaugh KP, Lemon KP. Staphylococcus aureus shifts toward commensalism in response to Corynebacterium species. Front Microbiol 2016;7:1230. $\underline{\text { Crossref }}$

39. Nakatsuji T, Chen TH, Narala S, et al. Antimicrobials from human skin commensal bacteria protect against Staphylococcus aureus and are deficient in atopic 
dermatitis. Sci Transl Med 2017;9:pii eaah4680. Crossref

40. Donia MS, Cimermancic P, Schulze CJ, Fischbach MA. A systematic analysis of biosynthetic gene clusters in the human microbiome reveals a common family of antibiotics. Cell 2014;158:1402-14. Crossref

41. Dowle C. Faecal microbiota transplantation: a review of FMT as an alternative treatment for Clostridium difficile infection. Bioscience Horizons The International Journal of Student Research 2016;9:hzw007. Crossref

42. Han M, Wang C, Liu P, et al. Dietary fiber gap and host gut microbiota. Protein Pept Lett 2017;24:38896. Crossref

43. Martinez-Augustin O, Sanchez de Medina F. Intestinal bile acid physiology and pathophysiology. World J Gastroenterol 2008;14:5630-40. Crossref

44. Sharma S, Erickson KM, Troutman JM. Complete tetrasaccharide repeat unit biosynthesis of the immunomodulatory Bacteroides fragilis capsular polysaccharide A. ACS Chem Biol 2017;12:92-101. $\underline{\text { Crossref }}$

45. LeBlanc JG, Milani C, Savoy de Giori G, Sesma F, van Sinderen D, Ventura M. Bacteria as vitamin suppliers to their host: a gut microbiota perspective. Curr Opin Biotechnol 2013;24:160-8. Crossref

46. Koren O, Goodrich JK, Cullender TC, et al. Host remodeling of the gut microbiome and metabolic changes during pregnancy. Cell 2012;150:470-80. Crossref

47. Neel JV. Diabetes mellitus: a "thrifty" genotype rendered detrimental by "progress"? 1962. Bull World Health Organ 1999;77:694-703; discussion 692-3.

48. Martínez-Hidalgo P, Hirsch AM. The nodule microbiome: N2-fixing rhizobia do not live alone. Phytobiomes 2017;1:70-82. Crossref

49. Thaiss CA, Zmora N, Levy M, Einav E. The microbiome and innate immunity. Nature 2016;535:65-74. Crossref

50. Sjogren K, Engdahl C, Henning P, et al. The gut microbiota regulates bone mass in mice. $\mathrm{J}$ Bone Miner Res 2012;27:1357-67. Crossref

51. Schirbel A, Kessler S, Rieder F, et al. Pro-angiogenic activity of TLRs and NLRs: a novel link between gut microbiota and intestinal angiogenesis. Gastroenterology 2013;144:613-23.

52. Mohajeri MH, La Fata G, Steinert RE, Weber P. Relationship between the gut microbiome and brain function. Nutr Rev 2018;76:481-96. Crossref

53. Heijtz RD, Wang S, Anuard F, et al. Normal gut microbiota modulates brain development and behavior. Proc Natl Acad Sci U S A 2011;108:3047. Crossref
54. O'Mahonya SM, Clarkea G, Borrea YE, et al. Serotonin, tryptophan metabolism and the brain-gutmicrobiome axis. Behav Brain Res 2015;277:32-48. $\underline{\text { Crossref }}$

55. Sakwinska O, Moine D, Delley M, et al. Microbiota in breast milk of Chinese lactating mothers. PLoS One 2016;11:e0160856. Crossref

56. Martín R, Lang S, Jimínez E, et al. Human milk is a source of lactic acid bacteria for the infant gut. $\mathrm{J}$ Pediatr 2003;143:754-75. Crossref

57. Milani C, Mancabelli L, Lugli GA, et al. Exploring vertical transmission of Bifidobacteria from mother to child. Appl Environ Microbiol 2015;81:7078-87. $\underline{\text { Crossref }}$

58. Sela DA, Li Y, Lerno L, et al. An infant-associated bacterial commensal utilizes breast milk sialyloligosaccharides. J Biol Chem 2011;286:11909-18. Crossref

59. Garrido D, Ruiz-Moyano S, Kirmiz SN, et al. A novel gene cluster allows preferential utilization of fucosylated milk oligosaccharides in Bifidobacterium longum subsp. longum SC596. Sci Rep 2016;6:35045. Crossref

6o. Ochman H, Worobey M, Kuo C-H, et al. Evolutionary relationships of wild hominids recapitulated by gut microbial communities. PLoS Biol 2010;8:e1000546. Crossref

61. Moeller AH, Caro-Quintero A, Mjungu D, et al. Cospeciation of gut microbiota with hominids. Science 2016;353:380-2. Crossref

62. Rosenberg E, Sharon G, Zilber-Rosenberg I. The hologenome theory of evolution: a fusion of neoDarwinism and Lamarckism. Environ Microbiol 2009;11:2959-62. Crossref

63. Dyall SD, Brown MT, Johnson PJ. Ancient invasions: from endosymbionts to organelles. Science 2001;304: 253-7. Crossref

64. McFadden GI, Van Dooren GG. Evolution: red algal genome affirms a common origin of all plastids. Curr Biol 2004;14:514-16. Crossref

65. Mackie RI. Mutualistic fermentative digestion in the gastrointestinal tract: diversity and evolution. Integr Comp Biol 2002;42:319. $\underline{\text { Crossref }}$

66. Sousa A, Frazão N, Ramiro RS, Gordo I. Evolution of commensal bacteria in the intestinal tract of mice. Curr Opin Microbiol 2017;38:114-21. Crossref

67. Nikoh N, Tanaka K, Shibata F, et al. Wolbachia genome integrated in an insect chromosome: evolution and fate of laterally transferred endosymbiont genes. Genome Res 2008;18:272-80. Crossref 
68. Gladyshev EA, Meselson M, Arkhipova IR. Massive horizontal gene transfer in bdelloid rotifers. Science 2008;320:1210-13. Crossref

69. Moran NA, Jarvik T. Lateral transfer of genes from fungi underlies carotenoid production in aphids. Science 2010;328:624-7. Crossref

70. Mitreva M, Smant G, Helder J. Role of horizontal gene transfer in the evolution of plant parasitism among nematodes. Methods Mol Biol 2009;532:51735. Crossref

71. Sieber KB, Bromley RE, Hotopp JCD. Lateral gene transfer between prokaryotes and eukaryotes. Exp Cell Res 2017;358:421-6. Crossref

72. Crisp A, Boschetti C, Perry M, Tunnacliffe A, Micklem G. Expression of multiple horizontally acquired genes is a hallmark of both vertebrate and invertebrate genomes. Genome Biol 2015;16:50. Crossref

73. Yue J, Hu X, Huang J. Horizontal gene transfer in the innovation and adaptation of land plants. Plant Signal Behav 2013;8:e24130. Crossref

74. Dupressoir A, Lavialle C, Heidmann T. From ancestral infectious retroviruses to bona fide cellular genes: role of the captured syncytins in placentation. Placenta 2012;33:663-71. $\underline{\text { Crossref }}$

75. Wagner GP, Kin K, Muglia L, Pavlicev M. Evolution of mammalian pregnancy and the origin of the decidual stromal cell. Int J Dev Biol 2014;58:117-26. Crossref

76. Hehemann JH, Correc G, Barbeyron T, Helbert W, Czjzek M, Michel G. Transfer of carbohydrate-active enzymes from marine bacteria to Japanese gut microbiota. Nature 2010;464:908-14. Crossref

77. Pitlik SD, Koren O. How holobionts get sick-toward a unifying scheme of disease. Microbiome 2017;5:64. $\underline{\text { Crossref }}$

78. Backhed F, Ding H, Wang T, et al. The gut microbiota as an environmental factor that regulates fat storage. PNAS 2004;101:15718-23. Crossref

79. Ridaura VK, Faith JJ, Rey FE, et al. Gut microbiota from twins discordant for obesity modulate metabolism in mice. Science 2013;341:1241214. Crossref

80. Turnbaugh PJ, Hamady M, Yatsunenko T, et al. A core gut microbiome in obese and lean twins. Nature 2009;457:480-4. $\underline{\text { Crossref }}$

81. Ley RE, Turnbaugh PJ, Klein S, Gordon JI. Human gut microbes associated with obesity. Nature 2006; 444:1022-3. Crossref

82. Castaner O, Goday A, Park Y-M, et al. The gut microbiome profile in obesity: a systemic review. Int $\mathrm{J}$ Endocrinol 2018;2018:4095789. $\underline{\text { Crossref }}$
83. Sze MA, Schloss PD. Looking for a signal in the noise: revisiting obesity and the microbiome. MBio 2016; 7(4). pii: eo1018-16. $\underline{\text { Crossref }}$

84. Aron-Wisnewsky J, Prifti E, Belda E, et al. Major microbiota dysbiosis in severe obesity: fate after bariatric surgery. Gut 2018 Jun 13. [Epub ahead of print] pii: gutjnl-2018-316103. $\underline{\text { Crossref }}$

85. Khan MJ, Gerasimidis K, Edwards CA, Shaikh MG. Role of gut microbiota in the aetiology of obesity: proposed mechanisms and review of the literature. J Obes 2016;2016:7353642. Crossref

86. Stephens RW, Arhire L, Covasa M. Gut microbiota: from microorganisms to metabolic organ influencing obesity. Obesity (Silver Spring) 2018;26:801-9. $\underline{\text { Crossref }}$

87. Harsch IA, Konturek PC. The role of gut microbiota in obesity and type 2 and type 1 diabetes mellitus: new insights into "old" diseases. Med Sci Med Sci (Basel) 2018;6(2). pii: E32. $\underline{\text { Crossref }}$

88. Cani PD, Amar J, Iglesias MA, et al. Metabolic endotoxemia initiates obesity and insulin resistance. Diabetes 2007;56:1761-72. $\underline{\text { Crossref }}$

89. Battson ML, Lee DM, Weir TL, Gentile CL. The gut microbiota as a novel regulator of cardiovascular function and disease. J Nutr Biochem 2018;56:1-15. Crossref

90. Bibbo S, Ianiro G, Dore MP, Simonelli C, Newton EE, Cammarota G. Gut microbiota as a driver of inflammation in nonalcoholic fatty liver disease. Mediators Inflamm 2018;2018:9321643. $\underline{\text { Crossref }}$

91. Qin Y, Roberts JD Grimm SA, et al. An obesityassociated gut microbiome reprograms the intestinal epigenome and leads to altered colonic gene expression. Genome Biol 2018;19:7. Crossref

92. Cani PD, Jordan BF. Gut microbiota-mediated inflammation in obesity: a link with gastrointestinal cancer. Nature Rev Gastroenterol Hepatol 2018;15:671-82. Crossref

93. Khan MT, Nieuwdorp M, Bäckhed F. Microbial modulation of insulin sensitivity. Cell Metab 2014; 20:753-60. Crossref

94. Maruvada P, Leone P, Kaplan LM, Chang EB. The human microbiome and obesity: moving beyond associations. Cell Host Microbe 2017;22:588-99. Crossref

95. Youngster I, Russel GH, Pinder C, Ziv-Baran T, Sauk J, Hohmann EL. Oral, capsulized, frozen fecal microbiota transplantation for relapsing Clostridium difficile infection. JAMA 2014;312:1772-8. Crossref

96. Juul FE, Garborg K, Bretthauer M, et al. Fecal microbiota transplantation for primary Clostridium difficile infection. N Engl J Med 2018;378:2535-6. $\underline{\text { Crossref }}$ 
97. Weingarden AR, Chen C, Bobr A, et al. Microbiota transplantation restores normal fecal bile acid composition in recurrent Clostridium difficile infection. Am J Physiol Gastrointest Liver Physiol 2014;306: G310-19. Crossref

98. Khoruts A, Dicksved J, Jansson JK, Sadowsky MJ. Changes in the composition of the human fecal microbiome after bacteriotherapy for recurrent Clostridium difficile-associated diarrhea. J Clin Gastroenterol 2010;44:354-6o.

99. Hamilton MJ, Weingarden AR, Unno T, Khoruts A, Sadowsky MJ. High-throughput DNA sequence analysis reveals stable engraftment of gut microbiota following transplantation of previously frozen fecal bacteria. Gut Microbes 2013;4:125-35. Crossref

100. Khoruts A, Sadowsky MJ. Understanding the mechanisms of faecal microbiota transplantation. Nat Rev Gastroenterol Hepatol 2016;13:508-16. Crossref

101. Rea MC, Sit CS, Clayton E, et al. Thuricin CD, a posttranslationally modified bacteriocin with a narrow spectrum of activity against Clostridium difficile. Proc Natl Acad Sci U S A 2010;107:9352-7. Crossref

102. Le Lay C, Dridi L, Bergeron MG, Ouellette M, Fliss IL. Nisin is an effective inhibitor of Clostridium difficile vegetative cells and spore germination. J Med Microbiol 2016;65:169-75. Crossref

103. Belkaid Y, Hand TW. Role of the microbiota in immunity and inflammation. Cell 2014;157:121-41. Crossref

104. Kostic AD, Xavier RJ, Gevers D. The microbiome in inflammatory bowel disease: current status and the future ahead. Gastroenterology 2014;146:1489-99. Crossref

105. Dicksved J, Halfvarson J, Rosenquist M, et al. Molecular analysis of the gut microbiota of identical twins with Crohn's disease. ISME J 2008;2:716-27. Crossref

106. Sepehri S, Kotlowski R, Bernstein CN, Krause DO. Microbial diversity of inflamed and noninflamed gut biopsy tissues in inflammatory bowel disease. Inflamm Bowel Dis 2007;13:675-83. $\underline{\text { Crossref }}$

107. Mcllroy J, Ianiro G, Mukhopadhya I, Hansen R, Hold GL. Review article: the gut microbiome in inflammatory bowel disease-avenues for microbial management. Aliment Pharmacol Ther 2018;47:26-42. Crossref

108. Williams BL, Hornig $\mathrm{M}$, Buie $\mathrm{T}$, et al. Impaired carbohydrate digestion and transport and mucosal dysbiosis in the intestines of children with autism and gastrointestinal disturbances. PLoS One 2011;6: e24585. $\underline{\text { Crossref }}$

109. Tomova A, Husarova V, Lakatosova S, et al. Gastrointestinal microbiota in children with autism in Slovakia. Physiol Behav 2015;138:179-87. Crossref

110. Strati F, Cavalieri D, Albanese D, et al. New evidences on the altered gut microbiota in autism spectrum disorders. Microbiome 2017;5:24. $\underline{\text { Crossref }}$

111. Theoharides TC, Asadi S, Patel AB. Focal brain inflammation and autism. J Neuroinflammation 2013;10:46. Crossref

112. Stolp HB, Johansson PA, Habgood MD, Dziegielewska KM, Saunders NR, Ek CJ. Effects of neonatal systemic inflammation on blood-brain barrier permeability and behaviour in juvenile and adult rats. Cardiovasc Psychiatry Neurol 2011;2011:469046. $\underline{\text { Crossref }}$

113. Hsiao EY, McBride SW, Hsien S, et al. Microbiota modulate behavioral and physiological abnormalities associated with neurodevelopmental disorders. Cell 2013;155:1451-63. $\underline{\text { Crossref }}$ 